\title{
ALGUMAS CONSIDERAÇÕES A RESPEITO DO LETRAMENTO NA PROVINHA BRASIL $^{1}$
}

\author{
SOME THOUGHTS ON THE LITERACY IN PROVINHA BRASIL
}

\author{
Carla Cristofolini ${ }^{2}$ \\ Doutoranda do Programa de Pós-graduação em Linguística - UFSC
}

\begin{abstract}
Resumo
Este artigo tem como objetivo discutir qual(is) o(s) conceito(s) de letramento embasa(m) e norteia(m) a "Provinha Brasil", teste padronizado nacional que avalia as habilidades de alfabetização e letramento de educandos no $2^{\circ}$ ano de escolaridade. Nessa discussão, aponta-se uma possível incoerência gerada no ínterim de duas perspectivas de análise: o letramento escolar (SOARES, 1998 e 2003) e o letramento enquanto fenômeno, prática social (BRITTO, 2003; STREET, 2003; KLEIMAN, 2005). Para tanto, relaciona-se essa discussão aos conceitos de letramento autônomo e ideológico (STREET, 2003), aos pontos de vista do letramento individual ou em grupos (BRITTO, 2003) e à noção de capital cultural (LAHIRE, 2008). Finalmente, busca-se discutir também quais as repercussões desses conceitos na educação, mais especificamente na alfabetização e na Provinha Brasil.
\end{abstract}

Palavras-chave: Letramento autônomo e ideológico. Letramento escolar. Provinha Brasil.

\begin{abstract}
The aim of the present work is to present which concepts of literacy support and guide Provinha Brasil, a standard national test which evaluate initial reading and literacy skills of $2^{\text {nd }}$ year students. Incoherence between the two different perspectives of analyzes, school literacy (SOARES, 1998 e 2003) and literacy as a phenomenon, social practice (BRITTO, 2003; STREET, 2003; KLEIMAN, 2005), was identified. Based on that, the discussion presented in this work is related to the concepts of autonomous and ideological literacy (STREET, 2003) as well as to individual and groups literacy (BRITTO, 2003) and cultural capital (LAHIRE, 2008). Finally, the effect of these concepts on education, especially in literacy and Provinha Brasil is also discussed in this study.
\end{abstract}

Key words: Autonomous and ideological literacy. Academic literacy. Provinha Brasil.

\footnotetext{
1 Artigo desenvolvido a partir das discussões da disciplina "Sociocognição e linguagem escrita", no Programa de Pós Graduação em Linguística da Universidade Federal de Santa Catarina, ministrada pela professora Mary Elizabeth Cerutti-Rizzatti.

2 Fonoaudióloga, mestre e doutoranda em Linguística no Programa de Pós Graduação em Linguística da Universidade Federal de Santa Catarina.
} 


\section{INTRODUÇÃO: O LETRAMENTO E OS TESTES PADRONIZADOS}

Faz alguns anos que o Ministério da Educação vem adotando medidas avaliativas padronizadas, no intuito de avaliar a educação brasileira. Várias provas já foram aplicadas, em todos os níveis educacionais (inclusive, avaliações internacionais, no caso o PISA), iniciando pelo Exame Nacional de Cursos, conhecido como Provão (que buscava avaliar o ensino superior, substituído ao longo do tempo por outros instrumentos até chegar ao formato atual, o ENADE) até a implantação da Provinha Brasil, no ano 2008, que avalia questões pertinentes à alfabetização e ao letramento, de alunos no $2^{\circ}$ ano de escolaridade no Ensino Fundamental (em torno de oito anos de idade). Cada um desses instrumentos de avaliação tem seus propósitos e suas especificidades e não é objetivo deste artigo discutir cada um deles. Também não se pretende redimir, nem crucificar esses instrumentos; o interesse, neste momento, é discutir uma característica comum: todos são elaborados a partir de uma matriz de referência nacional (no caso do PISA, internacional) e aplicados da mesma forma em todo o território nacional. É evidente que todos os brasileiros deveriam ter habilidades leitoras e escritoras desenvolvidas da mesma forma em todo o país, mas, daí dizer que o letramento pode ser medido por avaliações padronizadas, através de questões de múltipla escolha, iguais para todos os estudantes do país, parece algo que merece uma discussão mais aprofundada.

Subjacente às matrizes de referência dessas provas, estão implícitos (algumas vezes explícitos) os diversos conceitos adotados (função da escola, teorias de aprendizagem, alfabetização, letramento, entre outros) e avaliados, bem como as teorias que os norteiam. Bonamino, Coscarelli e Franco (2002) pesquisaram os conceitos implícitos ao SAEB e ao PISA e concluíram que o SAEB tem como principal foco avaliar "o resultado da ação de ensinar ou de aprender a ler e escrever", pois tem como um dos seus objetivos fazer um diagnóstico do nível de letramento (educação) dos alunos, para que, com base nesses dados, o governo e as escolas tomem medidas que procurem sanar os problemas/deficiências encontrados. O PISA tem como objetivo verificar as habilidades relacionadas ao letramento na sua dimensão social, ou seja, a capacidade de os alunos lidarem, em vários níveis, com textos que circulam na sociedade ocidental (não é objetivo do PISA diagnosticar os problemas de cada país), ou seja, como o aluno coloca em prática as habilidades de leitura e escrita quando lida com textos do cotidiano.

Assim, o objetivo deste artigo é discutir qual(is) o(s) conceito(s) de letramento embasa(m) a "Provinha Brasil" e quais as repercussões desses conceitos na educação. Para tanto, faz uma revisão teórica dos materiais que compõem o kit da Provinha Brasil, com foco nas habilidades descritas como pertinentes ao letramento, buscando discuti-los e debatê-los, relacionando-os, principalmente, a conceitos como letramento escolar (SOARES, 1998 e 2003) e letramento enquanto fenômeno, prática social (BRITTO, 2003; STREET, 2003; KLEIMAN, 2005). Embora entenda-se a alfabetização como um dos processos continentes do letramento (CERUTTI-RIZATTI, 2009) e embora a Provinha Brasil avalie habilidades de letramento e de alfabetização, as discussões aqui centralizam-se em torno do letramento; conceitos e discussões específicas à alfabetização não perpassam os debates desse artigo, mesmo entendendo-se a relação alfabetização e letramento de fundamental importância à escola. Dessa forma, esse artigo tem um caráter reflexivo, apresentando os conceitos de letramento e os modelos 
autônomo e ideológico, enfatizando autores que relacionam letramento diretamente à escolarização; também apresenta-se, brevemente, a Provinha Brasil, principalmente seus objetivos e suas bases teóricas em relação ao letramento. Durante essas exposições, apresentam-se também algumas outras reflexões, inquietações, perguntas e questionamentos; alguns desses permanecerão sem respostas, pois são pontos que, em nosso ponto de vista, deveriam suscitam debates.

Observa-se também uma possível "incoerência" em relação ao letramento nas avaliações padronizadas. Resumidamente, a grande pergunta que parece revelar esta incoerência é: se o letramento é considerado o uso social da escrita (em poucas palavras, procura-se expandir este conceito no decorrer do texto), se é uma prática social (e também individual), como ele pode ser avaliado, mensurado ou medido através de uma prova padronizada, nacional, massiva? Continuando e ampliando a pergunta: $\mathrm{O}$ letramento, entendido como fenômeno social, antropológico, pode ser mensurável através de uma nota escolar, obtida a partir de questões de múltipla escolha, sem levar em consideração o sujeito que responde a essa prova?

\section{O(S) CONCEITO(S) DE LETRAMENTO E A PROVINHA BRASIL}

De acordo com Britto (2003, p 10) "o conceito de letramento tem recoberto uma gama variada de interpretações do fenômeno social da escrita, as quais, apesar de fortemente co-relacionadas, supõem diferentes objetos." Assim, o letramento, em uma perspectiva mais social, antropológica, pode ser entendido "[...] como um conjunto de práticas sociais que usam a escrita, como sistema simbólico e enquanto tecnologia, para objetivos específicos." (KLEIMAN, 1995, p 18-9). Já em uma perspectiva "escolarizada", o letramento é entendido como "o resultado da ação de ensinar e aprender a ler e a escrever." (SOARES, 1998, p 19) ou como "habilidades, conhecimentos e atitudes necessários ao uso efetivo e competente da leitura e escrita nas práticas sociais que envolvem a língua escrita” (SOARES, 2003, p 89).

É no ínterim dessas duas perspectivas que se observa a contradição das avaliações padronizadas; Soares (2003) tem seu foco no letramento escolar (entendido aqui como uma célula dentro dos mundos do letramento) e, ao que parece, a Provinha Brasil está estruturada a partir desse entendimento. Nesse caso, não haveria contradição. Mas quando amplia-se o conceito de letramento para a perspectiva antropológica, quando discutem-se os modelos autônomos e ideológicos e a relação entre letramentos global e local essa contradição parece se evidenciar.

Em Street (2003, p 2-3), encontram-se as definições dos modelos ideológico e autônomo de letramento. Cabe ressaltar que, de acordo com os autores, esses dois modelos não são dicotomizados mas sim, entrelaçados, com o modelo ideológico envolvendo o modelo autônomo. Assim, no modelo autônomo as pessoas aprendem a dominar o sistema de escrita (técnica, habilidade técnica e neutra) e esse conhecimento, por si só, teria efeitos sobre outras práticas sociais e cognitivas; nesse modelo, as suposições culturais e ideológicas são apresentadas como se fossem neutras e universais. Já o modelo ideológico propõe que o letramento deve ser entendido a partir de práticas sociais e ideológicas; o próprio domínio da técnica surge de forma situada, uma vez que "o engajamento no letramento é sempre um ato social". O modelo 
ideológico também não é neutro, entendendo o letramento a partir das variedades culturais, concebendo-o como processo variável. Enfim, nesse modelo, "importa entender a forma como as pessoas concebem/usam a leitura e a escrita".

Esses dois modelos têm implicações bastante profundas quando se propõe a entender e discutir o letramento na escola. Para Kleiman (1995), o letramento escolar é baseado no modelo autônomo, concebendo a aquisição da escrita como um processo neutro, independente de considerações contextuais e sociais. O próprio Street (2003) coloca que a adoção do modelo autônomo de letramento é uma forma de privilegiar as elites escolarizadas. Por sua vez, a adoção do modelo ideológico permite que os pesquisadores se abstenham do julgamento e que entendam o letramento das populações e dos contextos sociais.

Em outras palavras, ao adotar o modelo autônomo, indiretamente diz-se que há um padrão de letramento ao qual todos devem chegar; que algumas práticas de letramento são melhores que outras e, consequentemente, outras são piores, menores. E também que o letramento pode ser mensurado, classificado, qualificado. Parece, então, que a Provinha Brasil está ancorada no letramento escolar e mais, no modelo autônomo de letramento. De acordo com o caderno "Passo a Passo" (2009), que acompanha o kit da Provinha Brasil $2009^{3}$, a Provinha é uma avaliação padronizada, nacional, que avalia as habilidades relativas à alfabetização e ao letramento inicial dos estudantes, visando um diagnóstico do nível de alfabetização dos alunos, ainda no início do processo de aprendizagem. A Provinha foi elaborada a partir de uma "Matriz de Referência para a Avaliação da Alfabetização e do Letramento Inicial", onde são consideradas como imprescindíveis para o desenvolvimento da alfabetização e do letramento as habilidades agrupadas em torno dos seguintes eixos: compreensão e valorização da cultura escrita; apropriação do sistema de escrita, leitura, escrita e desenvolvimento da oralidade. Dadas as características metodológicas da Provinha, só os primeiros três eixos foram contemplados na avaliação. A Provinha Brasil, então, consiste em 24 questões de múltipla escolha, com quatro opções de resposta; sua correção se dá por forma de gabaritos, gerando uma "medida quantitativa que possui um significado qualitativo" (PASSO A PASSO, 2009, p 14), que classifica o desempenho dos alunos em 5 níveis, conforme o número de acertos.

Como já comentado no início deste trabalho, o objetivo aqui é somente discutir as implicações de uma avaliação padronizada nos modelos de letramento e algumas de suas possíveis implicações para a escola; portanto, esta breve explanação sobre a Provinha somente situa um possível leitor acerca da avaliação, não a esgota. Não cabe, aqui, aprofundar outras questões pertinentes à Provinha, nem as habilidades relativas à alfabetização avaliadas pelo instrumento, mesmo entendendo-se a alfabetização como um dos conteúdos do letramento (CERUTTI-RIZZATTI, 2009) e de fundamental importância.

\footnotetext{
${ }^{3}$ Kit enviado às escolas participantes (a adesão das redes e escolas é voluntária), contendo 6 cadernos: Passo a passo, Caderno do aluno, Caderno do professor/ aplicador I: Orientações Gerais; Caderno do professor/ aplicador II: Guia de Aplicação; Guia de Correção e Interpretação de Resultados e Reflexões sobre a prática.

${ }^{4}$ Disponível no documento "PRÓ-LETRAMENTO" - Programa de Formação Continuada de Professores dos Anos/Séries Iniciais do Ensino Fundamental.
} 
Retomando a matriz de referência sobre a qual está estruturada a Provinha Brasil, encontramos a forma como letramento é entendido: como "as possibilidades de usos e funções sociais da linguagem escrita, isto é, o processo de inserção e participação dos sujeitos na cultura escrita" (PASSO A PASSO, 2009, p 11). Depois, temos, dentre os principais objetivos da Provinha (Passo a passo, 2009, p 14): "avalia as habilidades [...] do letramento". Que habilidades são estas? No eixo "Compreensão e valorização da cultura escrita" (um dos eixos da Matriz de Referência da Provinha Brasil, encontrada no Pró-Letramento (2008, p 18), as habilidades descritas são:

- "Conhecer, utilizar e valorizar os modos de produção e de circulação da escrita na sociedade;

- Conhecer os usos e funções sociais da escrita;

- Desenvolver capacidades necessárias para o uso da escrita no contexto escolar:

- Saber usar objetos de escrita presentes na cultura escolar,

- Desenvolver capacidades específicas para escrever."

Ainda de acordo com o Pró-Letramento, esses são "alguns fatores e condições essenciais à integração dos alunos no mundo letrado. Trata-se do processo do letramento, que deve ter orientação sistemática, com vista à compreensão e apropriação da cultura escrita pelos alunos" (2008, p 18).

Assim, para a avaliação dessas habilidades, algumas questões da Provinha Brasil envolvem portadores de textos 5 , considerados "comuns" na sociedade: um convite para uma festa de aniversário, um cartaz da campanha de vacinação, um recado e uma capa de uma revista de passatempos (questões ilustradas na Figura 1$)^{6}$.

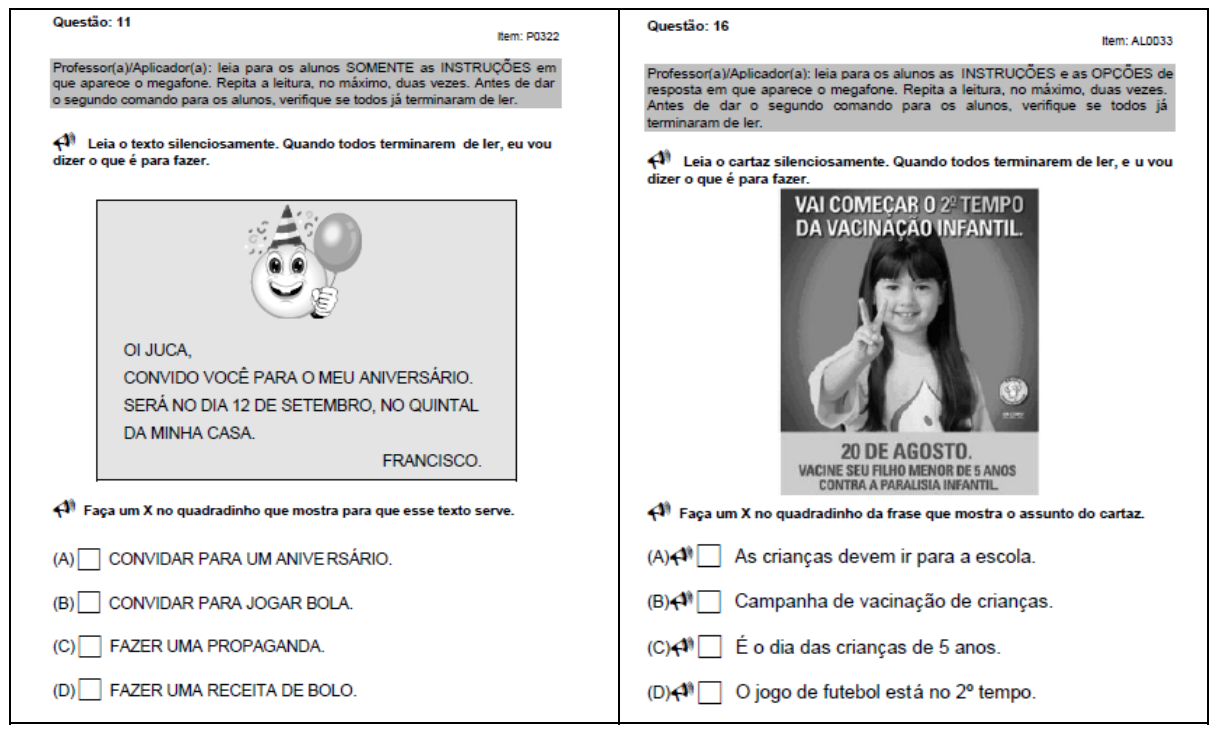

\footnotetext{
${ }^{5}$ Outras questões envolvem decodificação de palavras isoladas, habilidades metalinguísticas e pequenos textos, com foco em leitura e interpretação.

${ }^{6}$ Essas questões são referentes à edição 2008.I da Provinha Brasil.
} 


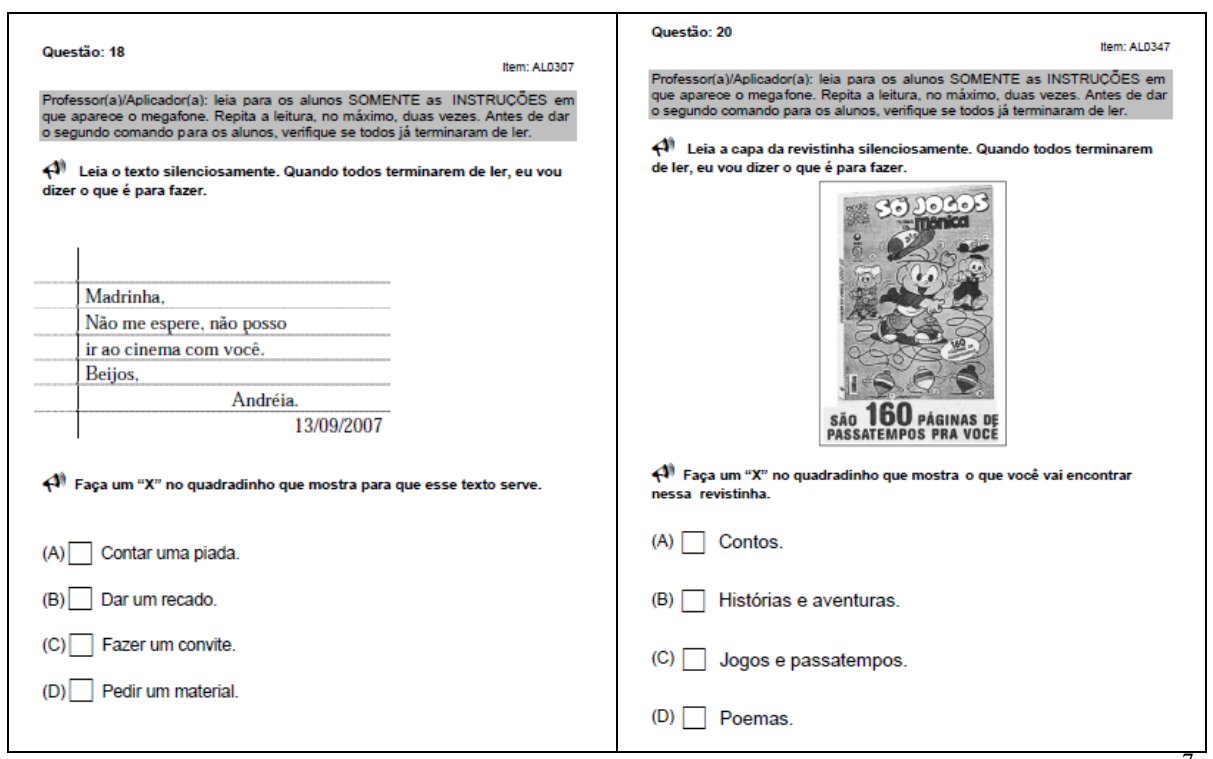

FIGURA 1: Questões da Provinha Brasil que envolvem portadores de texto ${ }^{7}$

No parágrafo anterior, foi destacado o termo "comuns", pois estes portadores são comuns a quem? Em que locais eles circulam? Com que propósitos? Eles circulam igualmente em todos os ambientes sociais? Têm a mesma representação para todos os sujeitos? E, principalmente, qual a relação da criança que está respondendo a prova com esses portadores?

As respostas a essas questões parecem refletir a adoção do modelo autônomo e, talvez consequentemente, a incoerência que se observa entre a teoria e a prática adotada pelas avaliações padronizadas. Como se pode entender a relação que a criança tem com a leitura e a escrita a partir de questões massivas, consideradas universais para todas as crianças brasileiras? Como, através de algumas poucas questões de múltipla escolha, é possível mensurar o letramento enquanto fenômeno social? Essa mensuração pode ser possível quando entendemos o letramento através do modelo autônomo: há um padrão de letramento, definido a priori, no qual todos devem acessar, da mesma forma, independentemente de quem sejam os sujeitos e de que relação têm com a escola. De acordo com Kleiman (1995, p 20), a maioria das práticas de escrita na escola ancoramse no modelo autônomo de letramento, onde "há apenas uma maneira de o letramento ser desenvolvido, sendo que essa forma está associada quase que causalmente com o progresso, a civilização, a mobilidade social". Então, se pensarmos que o letramento ideológico considera a leitura e a escrita como práticas sociais e não como atividades com fins em si mesmas e que a Provinha Brasil é um instrumento padronizado, que busca atingir igualmente todas as crianças da grande diversidade de escolas do país, a incoerência se evidencia; como considerar as muitas diversidades sociais em um instrumento avaliativo padronizado, massivo?

Neste ponto, é preciso ter cuidado para não cair no relativismo (como já apontado por Street, 1993). Claro que compreender um cartaz da campanha da vacinação é importante para todas as crianças de todo o país, não importando o meio social onde ela vive. Mas, se a criança errar a(s) questão(ões), por vários e diversos fatores (inclusive por não ter

\footnotetext{
${ }^{7}$ Disponível em: http://provinhabrasil.inep.gov.br; acesso em janeiro de 2010.
} 
se apropriado do código escrito ou por estar cansada), pode-se dizer que ela é menos letrada que a criança que acertou? Ou que seu letramento é inferior, pior?

Outro ponto que, novamente sob o ponto de vista defendido aqui, ressalta uma certa incoerência é a relação entre letramento visto sob a perspectiva individual e em grupos. Para Britto (2003) o letramento em grupos deve ser entendido como uma forma de organização social, de produção e intercâmbio de produtos, de estabelecimento de uma cultura, valores e padrões de comportamento e não como uma simples somatória de competências e habilidades individuais, desconsiderando que o conhecimento é circunscrito às condições históricas. Tinoco (2008) também defende essa posição, dizendo que o letramento deve ser compreendido nas diferentes práticas sociais e não apenas como um conjunto de habilidades a serem ensinadas ou aprendidas. Os significados que a escrita assume para um grupo social são social e culturalmente determinados, dependendo dos contextos e instituições em que ela foi adquirida (KLEIMAN, 2005). Lahire (2008, p 20) inclusive questiona "se os meios populares não se distinguem entre si do ponto de vista de sua relação com a escrita". Então, como pesquisar as "habilidades do letramento", enquanto fenômeno social, apenas com avaliações padronizadas, massivas, gerando um número que reflete a média de acertos na turma?

Assim, ao olhar para a Provinha Brasil, não se percebe, no teste, esta preocupação de Brito (2003), nem a preocupação em entender o letramento sob a ótica do grupo. O letramento da turma é entendido a partir da média de acertos das questões (correndo-se o risco de homogeneizar o que, por natureza, é diferente) ou, como diz Britto (2003), como a simples somatória de competências e habilidades individuais dos alunos.

Sobre como entender os resultados objetivos da correção da Provinha, além de trazer instruções de como realizar a avaliação quantitativa das respostas dos alunos (como aplicar o gabarito e como classificar os alunos), o caderno "Reflexões sobre a prática" (2009, p 9) coloca que o professor deve procurar analisar e compreender as respostas equivocadas dadas pelos alunos, buscando as hipóteses e/ou os conflitos cognitivos dos alunos. "Somente nesta perspectiva se torna possível realimentar o processo de aprendizagem e efetuar intervenções que favoreçam a retomada e a consolidação das capacidades que não foram ainda desenvolvidas. Desse modo, as dificuldades possibilitam a verificação de conceitos e estratégias utilizadas pelas crianças na resolução das atividades propostas no teste." Observa-se, novamente, que o escopo da interpretação da Provinha recai sobre o individual. Claro que essa interpretação é importantíssima, traz dados importantes principalmente à alfabetização e deve ser feita. Mas, à luz do modelo ideológico de letramento, não é suficiente. Para entender o que a escrita representa para os alunos e de que forma ela circula entre os alunos e suas relações sociais, outras questões precisam ser levantadas. A primeira questão seria analisar e compreender como os alunos entendem e utilizam a linguagem escrita. Em que práticas de letramento a família desse aluno se envolve? E como ele se envolve nelas? Em que outras agências de letramento este aluno está inserido e envolvido? E como essas práticas estão relacionadas? São convergentes ou divergentes às práticas de letramento da escola? Ou seja, é necessário entender a "sociologia individual", como propõe Lahire (2008) ao pesquisar o capital cultural das famílias, comparando-o com o da escola (o que não deixa de ser, de certa forma, a relação entre o letramento local - da 
família - com o global - o preconizado pela escola). “A nosso ver, só podemos compreender os resultados e os comportamentos escolares da criança se reconstruirmos a rede de interdependência familiar através da qual ela constitui seus esquemas de percepção, de julgamento, de avaliação, e a maneira pela qual esses esquemas podem "reagir" quando "funcionam" em formas escolares de relações sociais" (LAHIRE, 2008, p 19).

É provável que esteja subentendido que, como a professora de sala é quem aplica, corrige e interpreta os dados da Provinha Brasil, ela tenha o conhecimento profundo do perfil de sua turma, dos diversos "capitais culturais" com os quais se depara em sala de aula. Não generalizando, muito menos apontando culpados, sabe-se que, dadas as condições da maioria das escolas públicas brasileiras, não é o que se observa. Assim, os dados gerados pela Provinha Brasil podem transformar-se em uma arma de dois gumes. Ao mesmo tempo em que fornecem informações valiosas principalmente sobre o processo de alfabetização dos alunos podem levar a interpretações parciais, distorcidas e/ou equivocadas sobre o letramento e também sobre a própria alfabetização.

Talvez, um exemplo brasileiro de avaliação do letramento que, novamente sob o ponto de vista defendido nesse artigo, aproxime-se do que propõe Lahire (1995) e Street (2003) seja o INAF (Indicador de Alfabetismo Funcional). Essa pesquisa, realizada desde 2001, entende a leitura e a escrita como uma prática social complexa, abarcando suas diversidades, dimensões políticas e implicações ideológicas. O INAF avalia habilidades necessárias para viver em uma sociedade letrada, exercendo com autonomia seus direitos e responsabilidades (INAF/BRASIL, 2009). Segundo Ribeiro (2004) a opção do INAF em não avaliar somente as habilidades, mas também as práticas e as representações das pessoas sobre a leitura e a escrita, nas diversas esferas de letramento (esfera doméstica, do trabalho, do lazer, da participação cidadã, da educação e da religião) é que reflete o envolvimento do letramento na avaliação. Outro dado interessante do INAF é que ele não avalia somente a população em idade escolar (sua população alvo são brasileiros entre 15 e 64 anos de idade).

Um ponto nesta discussão ainda precisa ser retomado, o letramento escolar. Defendeuse aqui que a avaliação do letramento, da forma que está colocado na Provinha Brasil, é incoerente com a perspectiva ideológica do letramento. Porém, quando são analisados os teóricos que abordam o letramento escolar, essa contradição não parece ser tão evidente, uma vez que o letramento escolar pode ser mensurado (TINOCO, 2008). Retornemos, então, a definição de letramento, numa perspectiva escolar: "o resultado da ação de ensinar e aprender as práticas sociais de leitura e escrita." (SOARES, 1998, p 39) ou "habilidades, conhecimentos e atitudes necessários ao uso efetivo e competente da leitura e escrita nas práticas sociais que envolvem a língua escrita" (SOARES, 2003, p 89). De acordo com Tinoco (2008, p 68), essas definições "pressupõem saberes, atitudes e comportamentos de uma pessoa que, por ter-se apropriado da escrita, consegue oferecer determinadas respostas a determinadas demandas". A autora diz ainda que a adoção dessa concepção de letramento permite que ele possa ser mensurado por parâmetros definidos para cada série, nível ou grau de escolaridade.

Soares (2003) coloca que a relação de equivalência entre letramento e escolaridade pode ser dada por dois processos, ambos de inferência ou suposição: no primeiro, parte-se do grau de instrução para deduzir o nível de letramento de um sujeito; no segundo, parte-se 
das habilidades de letramento que o sujeito apresenta para relacioná-las aos graus de instrução. Quando se estabelece a equivalência entre os níveis de escolarização e os níveis de letramento, parte-se do pressuposto que, quando o sujeito alcança determinado nível de instrução ele não adquiriu somente a tecnologia da escrita (tornando-se alfabetizado), mas também terá se tornado letrado, ou seja, terá adquirido as competências básicas necessárias ao uso das práticas sociais de leitura e escrita. Já, para avaliar o letramento pelo critério do grau de instrução, partem-se de definições arbitrárias da equivalência entre determinado grau de escolaridade e o nível de letramento considerado satisfatório; nessa abordagem, considera-se nível satisfatório de letramento a conclusão da $4^{\mathrm{a}}$ série do ensino fundamental.

\section{CONSIDERAÇÕES FINAIS: UM PONTO DE VISTA SOBRE O LETRAMENTO NA PROVINHA BRASIL}

Mesmo que a Provinha Brasil seja focada no letramento na esfera escolar, acredita-se que a questão de entender o letramento é muito mais complexa e que as possíveis tentativas de mensurá-lo deveriam ser extremamente criteriosas e cuidadosas, a fim de não gerar e/ou aprofundar ainda mais a distância entre as diferentes manifestações do letramento. Com isso, de forma alguma, afirma-se que pessoas em locais diferentes têm capacidades diferentes e/ou que "mereçam" letramentos melhores ou piores. Também não se assevera que não é importante que a criança leia e compreenda um cartaz de vacinação, por exemplo, em qualquer canto do país. Tampouco afirma-se que, já que as comunidades são diferentes, apresentam letramentos diferentes, devem ter educação de qualidade diferente. Não se pretende nem romantizar os letramentos locais (conforme já alertou Street, 2003), nem dizer que o letramento de determinadas comunidades são menores. Isto seria, novamente, cair no relativismo. Busca-se, sim, que essas questões sejam tratadas com conhecimento e não apenas por estarem "na moda". Algumas iniciativas, como se entendem as avaliações padronizadas, são repletas de boas ações e intenções, e podem sim ser instrumentos valiosos para a melhoria da educação, dependendo da forma com que elas são tratadas e, principalmente, como são entendidas, interpretadas e utilizadas pelas escolas e pelos professores.

Mas também surge outra questão: se, em alguns estratos sociais, a escola é considerada a principal agência de letramento (KLEIMAN, 2005), quais as implicações de se adotar, em uma avaliação nacional padronizada como a Provinha Brasil, que, em última instância, serve de "modelo" de uma boa avaliação aos professores, o modelo autônomo de letramento?

As respostas para essas questões e para esses dilemas talvez estejam na mudança de perspectiva, estendendo-se aos conceitos preconizados pelo modelo ideológico. Nesta perspectiva, os "correlatos cognitivos da aquisição da escrita na escola devem ser entendidos em relação às estruturas culturais e de poder que o contexto de aquisição da escrita na escola representam" (KLEIMAN, 1995, p 39). Ao mesmo tempo, quando se fala de letramento escolar, Kleiman (2005, p 32) coloca que, apesar da escola separar as práticas de letramento de suas esferas de atividade e didatizá-las, isto não significa que não sejam situadas; elas são situadas na escola, com objetivos sociais relevantes para os participantes da prática; "as práticas de letramento escolares visam ao desenvolvimento 
de habilidades e competências do aluno e isso pode, ou não, ser relevante para o estudante".

Desse modo, Tinoco (2008) coloca que não há um letramento padrão, para o qual exista uma proposta pedagógica que possa ser aplicada a todas as escolas indistintamente. $\mathrm{O}$ conceito "mundos de letramento", conforme a autora, leva a entender os múltiplos letramentos, situados nas práticas sociais de leitura e escrita, nas diferentes esferas de atividade, orientados por propósitos comunicativos particulares, o que, nesse ponto de vista, complementaria as informações dadas pela Provinha Brasil, trazendo e somando a dimensão sócio-histórica e cultural à dimensão cognitiva, permitindo um melhor entendimento do processo de aquisição de leitura e escrita.

Em tempo: a Provinha Brasil visa avaliar as habilidades relativas à alfabetização e ao letramento inicial dos estudantes (PASSO a PASSO, 2009). No ponto de vista discutido neste artigo, abordaram-se somente algumas questões relativas ao letramento. As questões relacionadas à alfabetização, embora pertinentes e importantíssimas, foram relegadas, aqui, a segundo plano. Não se afirma, com isso, que o domínio do código seja menos ou mais importante (novamente, o relativismo); apenas não foi esse o objetivo da discussão. Aliás, embora a Provinha Brasil se proponha a avaliar as habilidades relativas ao letramento e à alfabetização, efetivamente está focada na alfabetização (CRISTOFOLINI, 2010); também parece sim adequada a avaliar as habilidades de alfabetização, claramente habilidades individuais e passíveis de mensuração, nivelamento, classificação, diferente do letramento, quando entendido a partir de sua dimensão social, antropológica.

\section{REFERÊNCIAS BIBLIOGRÁFICAS}

BONAMINO, A.; COSCARELLI, C.; FRANCO, C. Avaliação e letramento: concepções de aluno letrado subjacentes ao SAEB e ao PISA. Educação e Sociedade, vol. 23, n. 81, p. 91-113, dez. 2002. Campinas, 2002. Disponível em $<$ http://www.cedes.unicamp.br>; acesso em jan 2010.

BRITTO, L. P. L. Educação e política - sobre o conceito de letramento. In:

Contra o consenso. Campinas: Mercado das Letras, 2003. p. 9-16

CRISTOFOLINI, C. Refletindo sobre a Artigo Provinha Brasil a partir das dimensões sociocultural, linguística e cognitiva da leitura. Manuscrito não publicado. 2010 .

KLEIMAN, Â. Modelos de alfabetização e as práticas de alfabetização na escola. In (org). Os significados do letramento. Uma nova perspectiva sobre a prática social da escrita. São Paulo: Mercado das Letras, 1995. p 15 - 61.

Preciso "ensinar" o letramento? Não basta aprender a ler e escrever? Série Linguagem e letramento em foco. Linguagem nas séries iniciais. Cefiel/IEL/Unicamp, 2005 .

LAHIRE, B. O sucesso escolar nos meios populares. São Paulo: Ática, 1995. 
GUIA de APLICAÇÃO. Provinha Brasil. Ministério da Educação. Instituto Nacional de Estudos e Pesquisas Educacionais Anísio Teixeira. Teste 1, primeiro semestre, 2009.

INAF/BRASIL. Indicador de alfabetismo funcional. Principais resultados. Ação educativa e Instituto Paulo Montenegro. 2009. Disponível em < http://www.ipm.org.br/download/ inaf_brasil2009_relatorio_divulgacao_final.pdf >; acesso em jan/2010.

PASSO a PASSO. Provinha Brasil. Ministério da Educação. Instituto Nacional de Estudos e Pesquisas Educacionais Anísio Teixeira. Teste 1, primeiro semestre, 2009.

RIBEIRO, V. M. Por mais e melhores leitores: uma introdução. In. (org). Letramento no Brasil. Reflexões a partir do INAF 2001. 2 ed. São Paulo: Global, 2004. p 9 - 32.

STREET, B. Abordagens alternativas ao letramento e ao desenvolvimento. Teleconferência Unesco Brasil sobre Letramento e Diversidade, outubro de 2003. Disponível em $<$ http://www.unisesi.org.br/portal/arquivos/biblioteca/12 > , acesso em out $/ 2009$.

SOARES, M. Letramento, um tema em três gêneros. Belo Horizonte: Autêntica, 1998. $128 \mathrm{p}$.

. Letramento e escolarização. In RIBEIRO, V. M. (org). Letramento no Brasil. Reflexões a partir do INAF 2001. 2 ed. São Paulo: Global, 2003. p 89 - 114.

TINOCO, G. A. Mundos de letramento de professores em formação no agreste norteriograndense. In: OLIVEIRA, M.S.; KLEIMAN, Â. Letramentos múltiplos. Natal: EDUFRN, 2008. p $63-92$. 